\title{
FRAY ANDRÉS DE OLMOS Y LA PENETRACIÓN DEL LUTERANISMO EN MÉXICO NUEVOS DATOS Y DOCUMENTOS
}

Es de todos nosotros bien conocida la excelsa labor llevada a cabo por el benemérito franciscano fray Andrés de Olmos, en los tiempos fundadores de la evangelización y del reconocimiento de las culturas aborígenes de México. Llegado a la ciudad capital de la Nueva España en 1528, acompañando a su primer obispo fray Juan de Zumárraga, el religioso seráfico pronto pasaría a ser figura clave de la implantación eclesiástica en el antiguo imperio de los mexicah. En algunas otras ocasiones hemos creído necesaria la indagación cuidadosa sobre su figura y ante todo sobre su obra clave, ya que en tantos y tantos terrenos Olmos es un iniciador ${ }^{1}$.

No dejará nunca de sorprendernos, tanto el joven inquisidor dedicado a la caza de brujas en Vizcaya antes de arribar a América, como el primer investigador etnográfico sobre la cosmogonía de los mexicah, quien abrió todos los caminos intrincados de una labor pre-antropológica tan delicada, o aun el autor de las primeras gramáticas de la lengua náhuatl y de la lengua huasteca, así como, por fin, el primer introductor en aquellos idiomas amerindios de algunos textos importantes de la predicación católica, que tanto habían de complicar el panorama de la catcquesis americana. El personaje es a la vez símbolo y clave de la empresa que forjara el México colonial.

${ }^{1}$ Véanse Georges Baudot, Utopia e historia en México. Los primeros cronistas de la civilización mexicana (1520-1569), Espasa-Calpe, Madrid, 1983, caps. 3 y 4, pp. 129-245; La pugna franciscana por México, Alianza Editorial-Consejo Nacional para la Cultura y las Artes, México, 1990, caps. 5 y 6, pp. 133-171; "Vanidad y ambición en el Tratado de los Pecados Mortales en lengua náhuatl de fray Andrés de Olmos", Estudios de Cultura Náhuatl, 20 (1990), 39-63; y Fray Andrés de Olmos, Tratado de hechicerías y sortilegios, paleografía del texto náhuatl, versión esp., introd. y notas de Georges Baudot, Instituto de Investigaciones Históricas y Centro de Estudios Mexicanos y Centroamericanos, UNAM, México, 1990. 
La documentación que ahora nos sale al paso nos parece interesante porque se ubica en un periodo muy yermo de información dentro de la biografía y de la obra del franciscano. Es decir, en los últimos años de su vida, en la segunda mitad del siglo xvI, en Tampico. Amén de que estos datos importan también porque son significativos de las inquietudes e incluso de las angustias que despertaba la posible introducción temprana en América de ideas y textos producidos por la Reforma'protestante, de aquellos "libros luteranos" que cualquier viajero oriundo de España podía vehicular.

Efectivamente, es un legajo de la sección Inquisición del Archivo General de la Nación de México (AGN) el que nos depara esta curiosa información sobre una hipotética tentativa de confiscación de libros luteranos que fuera, probablemente, una de las últimas actividades de fray Andrés. Los diez folios que aquí nos interesan corresponden a cuatro documentos de 1571 y 1572 que son testificaciones y declaraciones en un interrogatorio del Tribunal del Santo Oficio, presentado primero ante el mismísimo inquisidor Moya de Contreras, en México, el 15 de septiembre de 1571. Información que posteriormente entrañaría interrogatorios complementarios en Tampico, en 1572. Olmos, cuyo papel, como veremos, fue importante en este asunto, es declarado ya difunto ("que sea en gloria"), dentro de las fechas de dichos documentos inquisitoriales. Esto corresponde bastante bien con la fecha del fallecimiento de fray Andrés en Tampico que sugerimos en Utopia e Historia en México ${ }^{2}$. Es decir, el 8 de octubre de 1568 y no el 8 de octubre de 1571 que registraron fray Gerónimo de Mendieta, fray Juan de Torquemada y fray Agustín de Vetancurt. Es así comc en el segundo de nuestros documentos de hoy, fechado el $15 \mathrm{dc}$ septiembre de 1571, el declarante, Domingo Correa, confirma ya a: "...Fr. Andrés de Olmos, de la Horden de San Francisco, difunto..." Además, la evocación de los hechos registrados sitúa la actividad del franciscano en este proceso aún unos tres años antes, según este primer testigo, o sea en 1568, pero recordandc sucesos que según el último testimonio de dicha acta concurrer ocho o diez años antes, entre 1563 y $1561^{3}$.

El conjunto documental ofrece ante todo una denuncia con tra un tal Diego Ramírez, arriero, vecino de San Luis de Tampi co, a quien se imputaba la propiedad y la lectura cuidadosa y re

\footnotetext{
${ }^{2}$ Op. cit., p. 159.

${ }^{3} \mathrm{AGN}$, Inquisición, vol. 224, ff. $161 \mathrm{r}^{\circ}-171 \mathrm{v}^{\circ}$.
} 
guiar en su casa de "libros luteranos", los cuales podía haberse conseguido en un viaje reciente a Flandes o a España, según rezan los diversos testimonios. Entre los testigos figuran como personajes sobresalientes la propia esposa del incriminado Diego Ramírez, doña Inés de Saldaña, a quien fray Andrés de Olmos llevaba más o menos unos tres años negándole la absolución por no querer entregarle los supuestos "libros luteranos". Y, sobre todo, como testigo de cargo fundamental, el documento trae al propio cuñado de Inés de Saldaña, un tal Cristóbal de Frías, quien era en realidad el verdadero denunciante ante Olmos y quien había inducido al franciscano a actuar en el asunto. Negocio que debió de parecer lo suficientemente grave a nuestro fray Andrés, pues le llevó a escribir una carta urgente y solemne al mismísimo arzobispo de México y que lo tuvo preocupado varios años, hasta que la identidad de los libros sospechosos quedara esclarecida, y su poca importancia ampliamente demostrada, para final satisfacción personal del religioso seráfico.

Pero demos paso a los documentos mismos y a algunos pasajes claves de éstos, que extraemos del conjunto hallado en el AGN, con su debida identificación.

El primero de ellos (ff. $161 \mathrm{r}^{0}-162 \mathrm{v}^{\circ}$ ) es el acta final de testificación, recibida el 4 de enero de 1573 en el Santo Oficio y que resume ritualmente los interrogatorios seguidos, sin que ofrezcan mayor interés.

El segundo de nuestros documentos, crucial a nuestro ver, expone la trama real de las sospechas y su desarrollo jurídico. Dice así:

En la cibdad de México, sábado quinze días del mes de septiembre de mil y auinientos y setenta y un años, estando el Illmo. Sr. Inquisidor, doctor Moya de Contreras en el monasterio de Sto. Domingo, de la dicha cibdad, paresçió de su voluntad, sin ser llamado, y juró en forma de dezir verdad un hombre que dixo llamarse Domingo Correa, harriero, de hedad de veinte y cinco años, natural de Baiona, en Galizia, en los reinos de España, moço soltero, vecino desta cibdad, al tianguez de San Juan.

Dixo que, por descargo de su conciencia, viene a dezir y manifestar que oyó dezir a Fr. Andrés de Olmos, de la horden de St. Francisco, difunto, que un Diego Ramírez, harriero, vecino de St. Luis de Ve [?], Tampico, en la costa del norte, tenía libros luteranos y que dezían que los avía traído de Flandes el dicho Diego Ramírez y que después desto este declarante oyó dezir a Inés de Saldaña, muger del dicho Diego Ramírez, que el dicho fraile avía muchos dias que no 
la quería absolver sobre esto sino le dava los dichos libros. Y la dicha Inés de Saldaña dezía que no sabía dellos, a lo qual estaba presente sola una niña Isabel, de ocho años, hija de la dicha Inés de Saldaña.

El caso es que las acusaciones de Domingo Correa no pararon en estos hechos, que a fin de cuentas parecen haber correspondido con cierta realidad. Así, a estas insinuaciones sobre una posesión no comprobada de libros sospechosos, siguen acusaciones disparatadas de blasfemias muy extravagantes, que esta vez más bien parecen fruto de la imaginación desbordada del acusador $\left(\right.$ f. $\left.163 \mathrm{r}^{\mathrm{o}}\right)$ :

Item. Dixo que el dicho Diego Ramírez, estando en el arroio de Tampacal, catorze leguas más acá de Tampico, camino de México y Tanacusco [ sic] [?], le oió renegar de Dios y de sus santos y, diziendo: "no me hiziera Dios degollador de caros y salteador de caminos, el diablo me lleve a mí, y a mi muger, y a mis hijos y a toda mi hazienda"...

Evidentemente, este tipo de denuncia no agrega gran cosa a los datos que pretendemos explorar en esta ocasión. Más importantes son, en el folio siguiente $\left(163 \mathrm{v}^{\circ}\right)$, las indicaciones cronológicas y circunstanciales que subraya el interrogatorio de la Inquisición. Así:

... preguntado qué tanto tiempo ha que oyó dezir lo que dicho tiene al dicho fr. Andrés de Olmos y a la dicha Inés de Saldaña lo que tiene declarado. Dixo que lo del dicho fr. Andrés avrá que se lo oyó dezir tres años antes, más que menos en Tampico.

Preguntado en quépparte lo oió al dicho fr. Andrés, dixo que en el monasterio de St. Francisco de Tampico y que a la dicha Inés de Saldaña le oió dezir lo que della tiene dicho avrá tres años después que el dicho fr. Andrés le dixo lo que ha declarado...

Estas precisiones de fechas podrían indicarnos que los hechos y las sospechas acaecidos ocurrieron unos seis años antes de la denuncia, es decir, allá por 1566. La circunstancia de lo sucedidc también es interesante y nos aclara, una vez más, lo que ya sabíamos eran las actividades principales de fray Andrés en la Huasteca y en aquellos años: la difícil y problemática evangelización de los chichimecas de las fronteras de Florida. El texto, efectivamente, así reza a continuación: 
... preguntado con qué.ocasión el dicho fr. Andrés le dixo lo que tiene dicho.

Dixo que estavan hablando de unos y de otros y de los Chichimecas, como el dicho fraile quería ponerlos en que viniessen a la fe de Xristo. Y a este propósito le dixo que estava éste con un mal amo, que tenía libros luteranos...

Los fundamentos mismos y principales de la denuncia quedan incluidos en estos términos. Pero algunos detalles, a nuestro ver aún importantes, siguen en los folios siguientes de esta documentación. En efecto, en el mismo folio y un poco más lejos, Inés de Saldaña confiesa que su propio cuñado Cristóbal de Frías fue el denunciante del asunto ante Olmos y el iniciador de todo el proceso:

. . la dicha Inés de Saldaña, la qual dixo que el dicho Frías avía ido a dezir al dicho fr. Andrés [f. $165 \mathrm{r}^{\circ}$ ] cómo su marido Diego Ramírez tenía libros luteranos y no la quería absolver.

En realidad, los fundamentos mismos y concretos de la denuncia eran de lo más vagos, inconsistentes y livianos. Efectivamente, el mismo testigo declara su impotencia para definir claramente el cuerpo del delito (f. $164 \mathrm{r}^{\circ}$ ):

... dixo que no sabe mas que le veía tener libros grandes y pequeños que no sabe cuántos y que de ordinario le veía leer en un libro grande, que no sabe qué libro era... Dixo que leía alto y que al parescer hera aquel buen libro y que a la lectura açertava éste a estar presente algunas veces y otras, un Julio de Rodal, criado suio . .

Y añade que, si no había denunciado estos hechos luctuosos anteriormente era porque no existía oficialmente un Tribunal del Santo Oficio debidamente constituido.

Al cabo de un año, el 17 de noviembre de 1572, nos encontramos con la declaración del mismísimo Cristóbal de Frías, cuñado de Isabel de Saldaña y autor de todo el desaguisado.

El texto de este tercer documento empieza así (f. $167 \mathrm{r}^{\circ}$ ):

Estando el Pe fray Joan Verdugo, comisario del Tamohí [sic] y su districto, delegado del Sancto Officio de la Ynquisición de México, para hazer cierta información tocante a las cosas de la fe. En Tampico, digo, en la villa de San Luis de Tampico, hoy lunes a diez y siete dias de noviembre del mill e quinientos y setenta y dos años, llamado Christóbal de Frías, pareció ante mí, Christóbal de Frías, de hedad de 
treinta años poco más o menos, hombre de buen rostro y cuerpo y casado en la villa de San Luis de Tampico, el qual declaró que era nacido en esta tierra...

Después de los juramentos y rituales en vigor para este tipo de interrogatorio, Cristóbal de Frías declara sus sospechas, sus preocupaciones, y explica el pormenor detallado de su gestión con fray Andrés, que no deja de ser sorprendente por la importancia que este último concede a tal proceder. El texto sigue diciendo así $\left(167 \mathrm{r}^{\circ}\right)$ :

... Dixo que era verdad que avía oýdo dezir que Diego Ramírez leýa en un libro para sí, entre dientes, esto en su casa como en la cama y fuera della, de lo qual murmuraban los criados de su casa. Lo qual vino a oýdos de Christóbal de Frías y, teniendo algún escrúpulo dello, lo comunicó con el pe. fray Andrés de Olmos, que sea en gloria. Oýdo lo qual, el dicho padre lo escribió al sor. arçovispo de México, que sea en gloria, y así eserivió al dicho Christóbal de Frías mandándole que el dicho fuese a México, paresciese ante él. El qual lo hizo ansí y, parecido delante del qual le preguntó, descargándole la conciencia, que le dixese qué quería dezir o significar aquella carta que fray Andrés de $\mathrm{Ol}$ mos le avía enviado. La qual le mostró al dicho Christóbal de Frías y él respondió diziendo que en que Dios y en su conciencia que él no sabía más de que lo avía oýdo murmurar en el dicho pueblo de Tampico y que él, queriéndose satisfacer si avía alguna enfermedad en el negocio, procuró por las señas que oyó que tenía el dicho libro en que leýa el dicho Diego Ramírez y vino a saber de cierta esciencia [sic] que era la Summa navarra, porque él mesmo lo tocó con sus manos y le vio con sus ojos...

La razón de estas sospechas parece haber sido, primero, un viaje reciente a España del incriminado (ibidem):

. . es que el ombre venía de España y, como en ella havía entrado esta desaventura de luteranos, dixo le havía oýdo dezir que leýa un libro a solas como de suso está dicho, y que podría ser algún libro sospechoso...

La curiosidad del inquisidor, que parece no haber conocido límites en esta ocasión, nos depara por fin una evocación más sustancial de lo que era la vida del franciscano en estos últimos años de su vida, en Tampico. Efectivamente, en el folio siguiente $\left(168 \mathrm{r}^{\circ}\right)$ hallamos que: 
... preguntado el dicho testigo que en qué. parte estaba el dicho fray Andrés quando se lo dixo y delante de quién. . . que viniendo el dicho fray Andrés de Güitlalpa [sic] [Hueytlalpan (?)], que llegó a un lugarcito del dicho Christóbal de Frías y que desde allí le envió a llamar, el qual fue luego por tenerle por padre y amigo, de la qual yda se trabeçó un Martín Pérez de la Mota, natural de La Palma, vecino desta villa de Tampico, y dixo que quería ir con él, a ver al padre. Y así juntos fueron al dicho lugar y después de acostado el dicho padre fray Andrés en su cama llamó a Christóbal de Frías, que lo tenía así de costumbre el dicho padre fray Andrés, por tenello por hijo, y como comenzaron a hablar en cosas de Diego Ramírez, vino a particularizarse el dicho testigo Christóbal de Frías, lo suso arriba dicho.

$Y$ no estando tan recatados como devieran, vino a entender el mesmo negocio el dicho Martín Pérez, porque salido de aý le dixo al mesmo Christóbal de Frías: "yo entendido todo lo que avéis tratado con el pe. fray Andrés"'. A lo qual respondió Christóbal de Frías: "por amor de Dios, que lo tengáis en secreto, porque podía ser mentira".

Púdolo oýr dicho Martín Pérez muy bien, porque la casa era mui pequeña y no estava fecha la división donde el padre dormía, sino unas cañas sin lodo, y por estar de la otra parte el dicho Martín Pérez, percivió todo lo que hablaron el dicho frayle y Christóbal de Frías...

Finalmente, estas conversaciones privadas, que por lo que vemos no guardaron toda la intimidad deseable, acabaron por reconocer que sabían más a chisme que a conciencia de un delito real. Efectivamente, el final del documento es edificante en este respecto. El propio Cristóbal de Frías nos termina por revelar la identidad de los libros incriminados (ibidem):

.. . supo que era la Summa navarra el uno de ellos, que era el de octavo, y quel de quarto supo que era un libro que se llamaba Orlando. .

con lo cual pareció quedar concluido el asunto y las angustias de nuestro franciscano (f. $168 \mathrm{v}^{\circ}$ ):

... y conocido el dicho Cristóbal de Frías que aquellos eran los dos libros que avía visto, quedó satisfecho, y asi fue al padre fray Andrés a satisfacerle, el cual quedó ni más ni menos satisfecho. . .

El último de los documentos del conjunto resulta ser una declaración complementaria de Inés de Saldaña que, sin mayores detalles, ratifica estos hechos, añadiendo, sencillamente, una precisión cronológica en el f. $169 \mathrm{v}^{\circ}$, en que explica que todo esto acae- 
ció con fray Andrés después de una confesión “habrá poco más o menos ocho o diez años".

No deben extrañarnos estos anhelos y estas preocupaciones de Olmos, velando por la perfecta catolicidad de sus fieles. Recordemos, en efecto y rápidamente, sus diversas actuaciones como celador de la ortodoxia católica a lo largo de su vida. Primero, como experto en brujerías y ayudante predilecto de fray Juan de Zumárraga en las delicadas circunstancias de la cacería de brujas en Vizcaya, ordenada en 1527. Luego, su actuación inquisitorial severa contra el señor amerindio de Matlatlán, en noviembre de 1539, de la que dio cuenta al arzobispo Zumárraga el 2 de enero de 1540. Y, por fin, no olvidemos su auténtica obsesión por la resurgencia vigorosa de las creencias prehispánicas, tal y como la expresa en el prólogo de su Tratado de hechicerías y sortilegios, de 1553.

La presencia de libros luteranos en las casas de los colonos de la Huasteca por esos años de 1561 a 1568 podía parecerle que revestía la mayor gravedad. Tengamos presente que el Concilio de Trento había concluido en 1563 y que la reacción ortodoxa que representa apuntó entonces el inicio decisivo de una persecución y destrucción metódicas de todas las huellas posibles de luteranismo o de pensamiento heterodoxo en los territorios en que imperaba la Inquisición española. Incluso, a contar de 1560 es cuando empieza plenamente la erradicación de las "facilidades" espirituales que podían parecer implicar el luteranismo, o incluso actitudes a veces allegadas como sería, por ejemplo, el erasmismo. Y esto, tanto más que fray Andrés de Olmos, probablemente menos milenarista que sus demás correligionarios dedicados a rescatar las culturas aborígenes de México, había bebido, de algún modo, en alguna que otra fuente "erasmista".

De este modo, ya hemos notado ${ }^{4}$ que el modelo español que sirvió de inspiración a Olmos para redactar en lengua náhuatl su Tratado de hechicerías y sortilegios en 1553 era el libro de quien había sido su compañero y probablemente su consejero en materia brujeril en 1527: fray Martín de Castañega, el Tratado de las supersticiones y hechicerias de Logroño, de 1529. Marcel Bataillon acertadísimamente hizo notar hace algunos años que el Tratado de las supersticiones... de Castañega:

${ }^{4}$ Véase La pugna franciscana por México, cap. 5, pp. 133-141, así como mi introducción al Tratado de hechicerias y sortilegios, pp. xxi-xxvii. 
... insiste dos veces sobre la doctrina del cuerpo místico, oponiéndola a la falta de unión de "la iglesia diabólica" y que en la misma obra (p. 4) tome a Erasmo como el escritor por antonomasia que sabe con la sabiduría de los antiguos hacer obra moderna (" . . todos los que escriben en estos nuestros tiempos, a los papeleros se pueden comparar, los cuales con papeles viejos, molidos y desatados, tornándolos a coger, con el marco de su arte hacen nuevo papel'). La Aprobación del tratado (pp. 159-160) es del canónigo erasmista Sancho Carranza de Miranda... ${ }^{5}$

Después de haber vuelto en 1533 con su Tratado de hechicerías $y$ sortilegios a las fuentes "erasmistas" de su juventud ¿ no sentiría fray Andrés, en 1561-1566, alguna que otra urgencia por retomar las vestiduras de la más exigente ortodoxia, concluido ya el Concilio de Trento y conocidos sus dictámenes, y mostrar así con un celo devastador y metódico su apego a las nuevas y estrictas normas? Y esto, viendo algún que otro fantasma luterano por los hogares de la Huasteca.

Recordemos una vez más que el ambiente político y espiritual de estas fechas es propicio para tales actitudes. El proceso en México del erasmista franciscano fray Alonso de Cabello es de 1572-1573. Las causas por luteranismo seguidas en México contra dos inmigrados de origen francés, el impresor Pedro Ocharte y su oficial Juan Ortiz son, respectivamente, de 1571 y 1572 , en que sufrieron tormento, el primero por haber " . . . acabado libros en que habían opiniones luteranas contra la veneración e intercesión de los santos, afirmando que a un solo Dios se ha de rezar y no a ellos..." y, el segundo, por " . . haber hecho, dicho, tenido y creído pública y secretamente errores de Lutero y sus secuaces, contra la veneración de los santos y festividades instituidas por nuestra Santa Madre la Santa Iglesia de Roma. . " Ante la inconsistencia de los cargos quedó luego absuelto Pedro Ocharte y Juan Ortiz votado a penitencia en auto público de fe, con destierro y pena pecuniaria ${ }^{6}$.

Cabría, para terminar con estas fantasmagóricas sospechas de fray Andrés de Olmos hacia el final de su vida, identificar claramente los dos libros incriminados: la Summa navarra y el Orlando. ¿Sería este último el Orlando furioso de Ariosto, cuyas afinidades nota.

${ }^{5}$ Marcel Bataillon, Erasmo y España, F.C.E., México, 1980, p. xv,

${ }^{6}$ Libros y libreros del siglo xvi, comp. Francisco Fernández del Castillo, F.C.E., México, 1982, pp. 85-245. 
espirituales con corrientes luteranizantes o erasmizantes podían en rigor haber parecido inquietantes? ${ }^{7}$

El primero de ellos acaso podría ser una compilación de escritos del conocido canonista español del siglo xvi Martín de Azpilcueta, umversalmente conocido entonces como "Doctor Navarro" y que, entre otras actividades, había sido profesor en las universidades de Toulouse, de Salamanca y de Coimbra. Fue uno de los grandes autores de la Reforma católica y crítico ortodoxo de Erasmo, aunque inspirado más de una vez en el espíritu erasmista. Depurador del culto, respetuoso de la liturgia, partidario de un esfuerzo especial en materia de restauración litúrgica, chocó con el sabio de Rotterdam sobre el problema de la oración privada, no sin condenar claramente más de una práctica supersticiosa de las costumbres católicas. Defensor del culto de los santos, supo condenar el sesgo supersticioso que a menudo conocía esta devoción. Como bien apunta Marcel Bataillon: "Con más respeto por la piedad de la gente humilde, el esfuerzo del Doctor $\mathrm{Na}$ varro no deja de estar dirigido en el sentido de Erasmo. . '"8 $\mathrm{Su}$ texto fundamental: Commento en romance a manera de repetición latina y scholástica de juristas. . . , revisión crítica del Modus orandi de Erasmo, gozó de una enorme autoridad y de muchas reimpresiones. Bien posible es que esa misma autoridad le diera el título de Summa navarra para los editores de la segunda mitad del siglo xvı. De todos modos, el libro gozaba de la más ortodoxa de las reputaciones.

Comprendemos así que fray Andrés de Olmos hubiese que. dado definitivamente satisfecho al conocer la excelencia de esta lectura, contraria a las violentas suspicacias que le habían llevado, en un primer tiempo, a negar durante años la absolución a una de sus hijas de confesión y a escribir, alarmado, al arzobispc de México.

Georges Baudot

Université de Toulouse II-Le Mirai.

7 G. M. Bertini, "L' Orlando furioso e la Rinascenza Spagnola”, La Nuova Italia, Firenze, 12 (1934), 12-14.

${ }^{8}$ Op. cit., p. 586. 